\title{
LA ESTERILIZACION EN EL CAMPO PENAL
}

\section{Dr. Jaime Bernal Cuéllar}

El problema de la esterilización femenina, desde el punto de vista jurídico penal, tiene algunas incidencias en el orden moral, ya que varias de las normas que describen los delitos, coinciden con preceptos de orden ético, lo cual solidifica el campo de acción del derecho penal.

En razón de que nuestra actual legislación penal viene rigiendo desde el año de 1936, y teniendo en cuenta que el aspecto científico de la esterilización es relativamente novedoso, es apenas lógico que en nuestro estatuto represivo no exista una norma específica que describa y sancione este tipo de conducta. Por tal motivo, es necesario señalar cuales son los elementos que dentro del Derecho Penal, se consideran indispensables para la estructuración del delito. Son pues, tres, tales elementos:

a) La tipicidad,

b) La antijuridicidad, y

c) La culpabilidad.

Respecto al primero de ellos, nos referimos cuando un determinado comportamiento humano coincide con una descripción de las normas que aparecen en el Código Penal, lo cual significa, que al realizar determinada conducta, descrita en un tipo penal, se está lesionando o poniendo en peligro un determinado interés, jurídicamente protegido en la norma violada.

Para poder determinar si una actuación cabe totalmente dentro de una norma penal, vale decir, para saber si tal proceder es típico o no, es necesario analizar si reúne todos $y$ cada uno de los elementos que integran la tipicidad, los cuales son: Sujeto Activo, quien realiza la conducta; Sujeto Pasivo, el titular del bien jurídico lesionado o puesto en peligro; la Conducta, es decir, el comportamiento que se considera violatorio del derecho, y que se encuentra plasmado en una norma; El Objeto Material, la persona o cosa sobre la cual recae el comportamiento, y El Objeto Jurídico, es decir, el interés que quiso protegerse con la norma. Reunidos estos elementos en un proceder humano, puede entonces hablarse de conducta típica.

Respecto al segundo elemento del delito, la antijuridicidad, nos referimas siempre que una conducta típi$c a$, se haya realizado contra derecho, sin que el comportamiento se encuentre amparado por alguna de las causales de justificación del hecho, que la misma ley consagra, como la legítima defensa, el estado de necesidad, la orden obligatoria de autoridad competente; otra, como el consentimiento del sujeto pasivo, también es admisible, a pesar de ser una 
creación doctrinal y jurisprudencial y no aparecer señalada en el código.

Con base en lo dicho, respecto de la antijuridicidad, podemos afirmar que el sujeto activo de una conducta típica, puede a la postre, no resultar responsable de su comportamiento, por haber actuado en el marco señalado por la ley como causal de justificación. Vale decir, que a pesar de encontrarnos frente a una conducta típica, ésta no es antijurídica, por haberse efectuado conforme a derecho, impulsado el sujeto activo por un estado de necesidad, o por haber obrado en legítima defensa.

El tercer elemento que integra la estructura del delito, la culpabilidad, es aquella por medio de la cual se quiere significar que el sujeto activo de un determinado comportamiento, ejecutó su acción con intención o propósito, es decir con dolo, o si simplemente la realizó por imprudencia o impericia, es decir con culpa, o si a pesar de haber querido un resultado delictivo, éste no se produjo en la forma deseada sino en una de mayor entidad, caso en el cual se hablaría de preterintención.

Con este somero esbozo de la estructura del delito, podemos hablar de la conducta desplegada por quien realiza la esterilización y las diferentes circunstancias que pueden rodear tal hecho.

Ahora bien, analizando en sí la esterilización de la mujer, y las consecuencias que esta puede acarrear, entramos a considerar si en un determinado momento podría darse, en dicha conducta, un delito de lesiones personales. Teniendo en cuenta que el artículo 371 del C. P. contempla el delito citado, y que para efectos de su sanción, discrimina la clase de lesión producida, por la incapacidad o por la deformidad física o las perturbaciones de carácter funcional o síquico, permanentes o transitorias a que dé lugar, y trayendo a colisión lo que los médicos especializados en la materia han conceptuado sobre las posibles lesiones que en el organismo humano pueden derivarse de la esterilización, tanto de carácter funcional, porque la mujer pierde la capacidad de procreación, como de carácter síquico, por lo que puede producirse en la siquis de la mujer al no estar habilitada para la función primordial, o por cualquier otra circunstancia que deje secuela sicológica y funcional; veamos si una de esas consecuencias, se subsume dentro del artículo precitado.

Desde el punto de vista de la conducta desplegada por quien realiza la lesión, en este caso la esterilización, que es el tema propuesto, podemos observar en primer lugar que el Código no contempla la conducta de la persona que se ocasiona ella misma la lesión, es decir, que quien se autolesiona, aunque tal proceder le ocasione consecuencias de diversa índole, graves o leves, no se hace penalmente responsable, porque su comportamiento se sustrae totalmente del campo jurídico; puede interesar su actuación al aspecto moral, pero en el campo jurídico penal, tal conducta no está descrita en los tipos penales que describen el delito de lesiones personales, por lo cual, no se puede iniciar investigación alguna.

Fero si resulta que la esterilización, es producida por un médico, tendríamos que analizar las circunstancias en que se produjo la lesión; es decir, si para que el científico obrara de esa forma, medió por ejemplo un estado de necesidad, como sería, evitar la muerte de la mujer a quien por su estado orgánico, le fuera mortal un embarazo, aunque la conducta 
produjera lesiones de cualquier naturaleza, no habría lugar a responsabilidad penal, dado que se obró bajo una de las ya enunciadas causales de justificación del hecho.

Si en cambio, el médico quiere realizar la esterilización, bajo circunstancias normales, pero debido a una impericia o a un descuido suyo, se produce la muerte de la mujer, no podríamos hablar de un hecho justificado, por ausencia de causal que excluyera la antijuridicidad, y su conducta sería típica, y habría que analizar entonces el tercer elemento estructurante del delito, o sea la culpabilidad, y tendría que imputársele el comportamiento a título de culpa.

Refiriéndonos no ya, a la persona que puede realizar una conducta delictiva, sino a la conducta en sí misma considerada, vemos como, cuando se realiza la esterilización por cualquiera de los métodos científicos existentes, explicados por los dactos en medicina, se está causando daños en el organismo, por consiguiente la actuación viola el artículo 371 del C. P., y las consecuencias del ilícito dependen de las secuelas que deje la esterilización, siempre y cuando coincidan con las que la misma norma describe, para sancionar el comportamiento.

Podemos concluir entonces, que siendo la esterilización, una lesión que en una $u$ otra forma, puede dejar consecuencias más o menos graves en el organismo, la conducta de quien lo realiza, siempre y cuando no esté amparada por una de las causales justificativas del hecho, puede encuadrar dentro del tipo penal que describe y sanciona las lesiones personales en el Código Penal.

\section{La Esterilización en el Campo Penal}

\section{Dr. Antonio José Cancino Moreno}

Habiendo enunciado, el Dr. Bernal, los elementos integrantes de todo delito, y analizado los dos primeros, la tipicidad y la antijuridicidad, nos dedicaremos ahora, al aspecto de la culpabilidad -tercer elemento-, vale decir, a la parte subjetiva del ilícito, sin que ello signifique que no toque aspectos referentes a la antijuridicidad.

Nos referimos, pues, a la intención con que se realiza determinada conducta delictiva; así, pues, el sujeto activo, con conocimiento de lo ilícito de su proceder, y por su propia voluntad, que quiere realizar un determinado comportamiento lesivo para la sociedad, y lo efectúa, actúa

dolosamente. Si en cambio, realiza la conducta sin tener en cuenta, cualquier circunstancia posible y evitable, que agrave su proceder, en el sentido de producir un resultado considerado como delictuoso, o aún habiendo tenido presentes esas circunstancias, pero por una $u$ otra razón, creyó poder salvarlas, una vez se presentaran, dándose también de esta forma un evento ilícito, diremos que actuó culposamente. Pero si resulta, que se quiere producir un resultado delictivo consagrado en la ley, y se realizan todas las etapas posibles para la consumación de la conducta deseada, y por circunstancias de diversa índole, se produce un resultado diferente al querido $y$ de consecuencias 
más graves, hablaremos entonces de una preterintención.

En cualquiera de estas tres formas, estaremos frente a una conducta culpable, sea a título de dolo, culpa o preterintención.

Pero así como la antijuridicidad, la culpabilidad tiene un aspecto negativo que la excluye, que tiene lugar cuando la conducta se realiza en circunstancias que configuran las causales de exculpación.

Tales causales son:

a) LA INCONSCIENCIA, es decir, cuando en el ser humano, no funcionan ni el mecanismo intelectivo, ni el volitivo.

b) EL ERROR, cuando falla el mecanismo intelectivo.

c) LA INSUPERABLE COACCION AJENA, cuando falla el mecanismo de la volición, y

d) EL CASO FORTUITO Y LA FUERZA MAYOR, que son circunstancias ajenas al conocimiento y la voluntad de cualquier hombre.

Con esta breve ilustración, y teniendo en cuenta lo expuesto por el Dr. Bernal, ejemplifiquemos las posibilidades que pueden presentarse.

Si el médico es obligado por cualquier persona a realizar la esterilización, bajo cualquier amenaza grave, aunque la operación deje secuelas graves y tal vez fatales, no podríamos decir que el sujeto que la realizó se tendría como culpable de un delito, toda vez que su conducta fue ejecutada bajo coacción ajena, elemento que es considerado como causal de exculpación. Igualmente sucedería si la circunstancia, por la cual se produjo la lesión, fue otra cualquiera de las causales enunciadas.
Teniendo en cuenta, entonces, que el aspecto central de esta conferencia es la esterilización, y partiendo de la base de que la conducta puede encuadrarse dentro del tipo penal que describe las lesiones personales, nos limitaremos a exponer, desde este punto de vista, las diferentes variantes de la conducta de quien realiza tal intervención y sus consecuencias en el campo penal.

En primer lugar, si se realiza la esterilización, y tal conducta llega a ser calificada como típica, antijurídica y culpable, no cabe la menor duda de que estamos en presencia de un delito, de manera, que la consecuencia penal de éste, es decir su sanción, se determinaría por el tipo de lesión que deje; pero si resulta que tal esterilización, dejó consecuencias tanto de carácter síquico, como de carácter funcional, con una incapacidad bastante considerable, se tendrá en cuenta la secuela más grave, para aplicar así, la sanción correspondiente.

Enfocando, por otra parte el problema, tanto desde el punto de vista del médico, como de la paciente, puede presentarse el caso de que el facultativo actúe con pleno consentimiento sobre el hecho de causar la esterilización a la mujer que también presta su consentimiento; tendremos, que el primero, no respondería penalmente, ya que se encuentra amparado por una causal doctrinal y jurisprudencial de justificación del hecho, cual es el consentimiento del sujeto pasivo; respecto de la mujer, no habría, como ya se anotó, ninguna incidencia de su conducta en el campo penal, pues nuestra legislación no contempla la autolesión, al menos en esta modalidad.

Es importante también señalar, ya que a ello se ha hecho referencia, 
que el consentimiento de la mujer para someterse a la esterilización, debe ser libre, consciente, capaz y expreso, es decir, que no puede deducirse de cualquier actuación ni de haberle dado un significado diferente a sus palabras. Aunque la ley no ha regulado el consentimiento del ofendido, una interpretación cuidadosa de los tipos contenidos en la parte especial del Código, referida a la índole y naturaleza del bien de protección, permite asegurar en muchos casos, su eficacia justificante. Lo decisivo es la disponibilidad del bien jurídicamente protegido, y el bien es disponible y su consentimiento eficaz, si su conservación solo interesa al titular.

Desde luego que el consentimiento del sujeto pasivo para que pueda convertirse en causal de justificación del hecho, no debe basarse o fundamentarse en aspectos mínimos, como cuando la mujer no quiere procrear por conservar su esbelta figura. Caso diferente es el de la Planificación Familiar referido a aquellas personas que por razones de carácter económi$c o$, social y cultural, no pueden responder a la obligación de educar y apoyar un hijo.

Para hacer un poco más comprensible el aspecto que hemos venido tratando es necesario ejemplificar. Bien, puede presentarse el caso de que sin el consentimiento de la mujer, se produce la esterilidad, dado que el facultativo actuó con el consentimiento del marido. Se darían varias hipótesis:

1. Si la intervención se realizó porque era absolutamente necesaria para preservar la vida de la mujer, estaríamos frente a un caso de justificación del hecho, y aunque la conducta fuera típica, no iría contra derecho, porque no sería antijurídica. Entonces, en este caso, a pesar de que no existe el consentimiento del sujeto pasivo, tanto el médico como el marido, se encontrarían frente al fenómeno del estado de necesidad, y lógicamente, para ninguno de los dos la conducta sería antijurídica.

2. Si en cambio, la esterilidad se produce únicamente por el acuerdo previo entre el médico y el marido, sin que medie ninguna circunstancia que justifique el hecho, ambos responderán por las consecuencias de la lesión que se produjo, a título de dolo.

3. Puede presentarse el caso de que a consecuencia de la esterilización, la mujer pierda la vida, evento en el cual, tanto el facultativo, como el marido, responderían del Homicidio Preterintencional, ya que la única intención era la de producir la esterilidad, pero se produjo un resultado diferente al querido $y$ de consecuencias más graves.

Respecto a la persona que realiza la intervención, en este caso el cirujano, puede presentarse la hipótesis, de que después de someter a la mujer a un examen, crea que es conveniente y necesaria la esterilización; si después de practicada ésta, se demuestra que el galeno se encontraba en un error se plantean entonces, dos posibilidades:

a) $\mathrm{Si}$ el error que sufrió el profesional, fue debido a negligencia $0 \mathrm{im}$ pericia, y con un poco de atención no hubiera incurrido en él, respondería del delito de lesiones personales a título de culpa.

b) Pero si resulta que el error no se debió ni a imprudencia ni a impericia del facultativo, y cualquier médico, dada la complejidad del cuerpo humano, hubiera podido incurrir en él, tenemos que estaría amparado por una de las causales de exclusión de la culpabilidad, cual es el error. 
También, me referiré en forma muy somera, al aspecto de la conducta omisiva, especialmente referida al aspecto moral, que también en este caso podría tocar el aspecto legal. Me refiero a ciertas entidades hospitalarias, que por razones de principio, se niegan a practicar la esterilización; es cierto que no es obligatorio que la entidad preste tal servicio, pero en ocasiones como cuando se hace absolutamente necesario producirla, para salvar una vida, por ejemplo, se convierte en un deber, no solo moral sino jurídico, ya que estamos en presencia de dos bienes o derechos, de los cuales uno necesariamente tiene que sacrificarse y debe ser el de menor entidad. Por tal razón, si en circunstancias, como la anotada, la entidad hospitalaria, se niega a prestar tal servicio, la persona que tomó la determinación, respondería penalmente por las consecuencias que sobrevengan.

Sobre este tema, en relación con el campo del Derecho Penal, existen otros interrogantes que resolver, pero en atención a la brevedad, decidimos con el Dr. Bernal, tocar los aspectos más importantes, con el fin de ilustrarlos sobre las consecuencias penales que se derivan de la conducta. 